\title{
A prática pedagógica de uma professora com estudantes surdos
}

Fabíola Morais Barbosa

MariaAparecida Pacheco Gusmão

\section{Resumo}

Neste artigo apresentamos o resultado de uma pesquisa qualitativa do tipo estudo de caso, realizada em uma escola pública no município de Ipiaú-BA acerca da prática pedagógica de uma docente no ensino de línguas utilizando o SignWriting $(S W)$. A pesquisa objetivou analisar a prática docente construída e vivenciada por uma professora no ensino do sistema $S W$ e as contribuições desse sistema no processo no ensino-aprendizagem de alunos surdos. Os dados evidenciaram que a prática desenvolvida pela professora propicia o processo de ensino-aprendizagem pelos estudantes.

Palavras-chave: Prática pedagógica; Estudantes surdos; Língua Brasileira de Sinais. 


\section{The pedagogical practice of a teacher with deaf students}

Fabíola Morais Barbosa Maria

Aparecida Pacheco Gusmão

\section{Abstract}

In this paper we present the results of a qualitative study of the case study, carried out in a public school in the municipality of Ipiaú-BA about the pedagogical practice of a teacher in language teaching using SignWriting (SW). The research aimed to analyze the teaching practice built and experienced by a teacher in the teaching of the SW system and the contributions of this system in the teaching-learning process of deaf students. The data show that the practice developed by the teacher provides the teaching-learning process by the students.

Keywords: Pedagogical practice, Deaf students; Brazilian Language of Signals 


\section{Introdução}

$\mathrm{Na}$ recordação dos sujeitos surdos sobre o seu processo educacional, a Libras foi sempre ensinada em segundo plano. Essa alteração não faz com que a Libras deixe de ser a primeira língua dos surdos, entretanto, inverte a ordem normal e coerente da aprendizagem. Assim, nos países que falam a língua portuguesa, a sua modalidade escrita foi ensinada para os surdos a fim de que aprendam a ler e escrever, fato que gerou muitas barreiras no processo comunicativo. Pois a estratégia eficaz seria alfabetizar os surdos em Libras (L1) e posteriormente ensinar o Português (L2) com metodologia própria, porque nessa perspectiva o aluno conseguiria ter um desenvolvimento melhor em sua aprendizagem, podendo estabelecer relação comparativa entre a Libras (sua L1, língua natural) e o Português (L2, modalidade escrita). Portanto, quando tratamos de inversão de valores sociopolíticos estamos visualizando a situação linguística da comunidade surda e inserindo-os na realidade educacional de um ouvinte, não havendo respeito e valorização social e política para este grupo.

Nesse sentido, a inversão metodológica é considerada uma consequência da anterior, ou seja, ao passo que se aplicam metodologias de ensino direcionadas para um grupo em outro, há claramente uma alteração. No caso dos surdos, quando estão em sala de aula recebendo orientações com base na metodologia de ensino para ouvintes, logicamente esse processo didático não será bem-sucedido ou eficaz.

É possível perceber que os ouvintes em fase de alfabetização ouvem uma palavra e escrevem, mas os surdos por não terem a audição como via de acesso, os fonemas não fazem sentido para eles, portanto, precisam memorizar a escrita das palavras. Assim o desenvolvimento da compreensão do processo da leitura e da escrita demanda muito esforço. Silva (2009, p. 50) afirma que "o surdo lê, mas não entende o que lê, não consegue construir o sentido do texto, tem o costume de ler as palavras isoladamente, sem considerar seu contexto, costuma sempre buscar a tradução para a língua de sinais". Essa consideração nos remete à ideia de que Libras não seja a língua natural, pois sempre é trabalhado com repetições para alcançar a compreensão das palavras e do vocabulário. A repetição é necessária para que o aluno memorize a palavra e seu significado relacionado com o sinal em Libras.

No caso das crianças surdas, a metodologia para ensino da modalidade escrita da língua oral precisa ser diferente, observando as especificidades do aluno, ou seja, as ações docentes precisam ser repensadas nesses aspectos e de acordo com dados de pesquisas conhecidas no meio acadêmico de estudos linguísticos da Libras, como os estudos de Stumpf (2005 e 2011), Wanderley (2015), e dentre outros. É possível atrelar a utilização do $S W$ com a didática do professor, como forma de aperfeiçoar o processo de alfabetização dos alunos surdos.

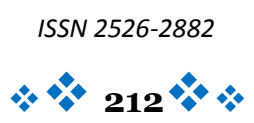


Neste artigo, apresentamos os resultados de uma pesquisa realizada em uma escola pública no município de Ipiaú-BA acerca da prática pedagógica de uma docente no ensino de línguas utilizando o SignWriting $(S W)$. A pesquisa objetivou analisar a prática docente construída e vivenciada por uma professora no ensino do sistema $S W$ e as contribuições desse sistema no processo no ensino-aprendizagem de alunos surdos.

\section{Metodologia}

Metodologicamente realizamos uma pesquisa qualitativa do tipo estudo de caso. Segundo Minayo (2002), a pesquisa qualitativa trabalha com o universo de significados, motivos, aspirações, crenças, valores e atitudes. Essa abordagem consiste em descrições detalhadas dos dados construídos com o objetivo de compreender o fenômeno pela sua descrição e interpretação.

A pesquisa foi realizada no CAPI (Centro de Apoio Pedagógico de Ipiaú). O CAPI está situado no centro da cidade de Ipiaú, no sul da Bahia. Esta cidade tem uma população de aproximadamente 43.00o habitantes (IBGE, 2010). A grande maioria dos alunos atendidos no CAPI é de baixa renda, tem famílias muitas vezes desestruturadas e/ou com baixa ou nenhuma escolaridade, o que dificulta o acesso à informação e na maioria dos casos moram em bairros periféricos e cidades circunvizinhas, o que dificulta a permanência nesta unidade escolar.

Pelo fato de estar localizada no centro da cidade, a vizinhança do CAPI é na grande maioria formada por estabelecimentos comerciais, escolas e poucas residências. Nesse sentido, a comunidade local não se envolve muito nas atividades e muitas vezes sequer sabe o que acontece naquela instituição. Entretanto, é fundamental perceber a relevância deste centro nesta cidade, pois alcança todas as parcelas da comunidade de forma gratuita, oferecendo atendimento especializado e acesso à informação para as famílias e para a própria sociedade.

O CAPI está organizado por áreas, de acordo com as especificidades de cada aluno, conforme a tabela abaixo:

Quadro 1 - Áreas de atendimento do CAPI

\begin{tabular}{|c|c|c|c|}
\hline \multicolumn{4}{|c|}{ Áreas de atendimento } \\
\hline $\begin{array}{l}\text { Altas habilidades/ } \\
\text { superdotação }\end{array}$ & Deficiências & $\begin{array}{c}\text { Transtorno global do } \\
\text { desenvolvimento }\end{array}$ & $\begin{array}{c}\text { Transtornos } \\
\text { funcionais específicos }\end{array}$ \\
\hline $\begin{array}{l}\text { Não há subdivisões } \\
\text { nesta área de } \\
\text { atendimento. }\end{array}$ & $\begin{array}{l}\text { - Cegueira } \\
\text { - Baixa Visão } \\
\text { - Deficiência } \\
\text { Auditiva } \\
\text { - Surdez } \\
\text { - Surdocegueira } \\
\text { - Intelectual } \\
\text { - Múltipla } \\
\text { - Física }\end{array}$ & $\begin{array}{l}\text {-Autismo } \\
\text {-Síndrome de } \\
\text { Asperger } \\
\text {-Síndrome de Rett } \\
\text {-Transtorno } \\
\text { Degenerativo da } \\
\text { Infância }\end{array}$ & $\begin{array}{lc}\text { - } & \text { Dislexia } \\
\text { - } & \text { Distorgrafia } \\
\text { - } & \text { Discalculia } \\
\text { - } & \text { Disgrafia } \\
\text { - } & \text { Transtorno de } \\
\text { Atenção } \\
\text { Hiperatividade }\end{array}$ \\
\hline
\end{tabular}

Fonte: organizado pelos autores com base no PPP (2017) da escola. 
Em 2017, ano de realização da pesquisa, o CAPI contava com um total de 68 funcionários, sendo 03 intérpretes de Língua Brasileira de Sinais, 07 professores do município, 22 professores temporários, 25 professores estaduais efetivos, 08 funcionários de serviços gerais, 01 funcionário de apoio administrativo e o1 secretária. Em relação aos alunos, observamos o quadro abaixo:

Quadro 2 - Quantitativo de alunos

\begin{tabular}{|c|c|}
\hline \multicolumn{2}{|r|}{ Alunos } \\
\hline Quantidade & Área \\
\hline 15 & Transtorno do espectro autista \\
\hline 17 & Baixa visão \\
\hline 15 & Cegueira \\
\hline 06 & Deficiência auditiva \\
\hline 50 & Surdez \\
\hline 129 & Deficiência intelectual \\
\hline 16 & Deficiência múltipla \\
\hline 07 & Deficiência física \\
\hline 255 & Total \\
\hline
\end{tabular}

Fonte: Organizado pelos pesquisadores com base no PPP (2017) da escola

Para a produção dos dados, contamos com os seguintes instrumentos e procedimentos: a) entrevistas semiestruturadas com a docente e cinco discentes surdos (as) envolvidos no processo de aprendizagem da escrita de sinais; b) análise dos planejamentos da professora e materiais didáticos dos alunos utilizados no processo ensino/aprendizagem do $S W$; c) observações na sala de aula; d) registro em fotografia dos materiais didáticos usados em todo o processo e filmagem das entrevistas com os alunos surdos e com a professora.

Foram gravadas entrevista semiestruturada com a professora Laura e cinco de seus discentes surdos. Mas antes de efetivar as gravações, a professora respondeu todas as questões propostas na modalidade escrita da Língua Portuguesa e depois gravou o vídeo em Libras. Por outro lado, os alunos surdos foram diretamente para a etapa de gravação em Libras.

As gravações de vídeos em Libras com as entrevistas foram de grande utilidade para melhor compreensão e desenvolvimento comunicativo. De acordo com Peter Loizos (2008, p.149), o registro em vídeo torna-se necessário "sempre que algum conjunto de ações humanas é complexo e difícil de ser descrito compreensivamente por um único observador, enquanto este se desenrola". Essa definição esclarece muito bem o tipo de entrevista utilizado na pesquisa, pois com a gravação foi possível ver e rever as entrevistas a fim de certificar as 
informações. Nesta etapa da pesquisa usamos como recurso comunicativo unicamente a Língua Brasileira de Sinais - Libras. Isso proporcionou melhor compreensão da linguagem.

Os documentos selecionados para a análise foram os arquivos das pastas dos alunos (cada um tem relatório desde quando iniciou os estudos no CAPI) atividades e materiais didáticos do processo de aprendizado de Libras pelo sistema da escrita de língua de sinais; planejamentos da professora a fim de perceber como acontece essa aplicação durante o processo ensino/aprendizagem do $S W$ na sala de aula; o plano de curso da área de surdez e os planos de aula. Por meio da triangulação dos dados, produzimos 04 categorias, conforme quadro a seguir:

\begin{tabular}{|c|c|c|c|}
\hline $\begin{array}{l}\text { 1.Organização pedagógica da } \\
\text { escola e das atividades } \\
\text { didáticas }\end{array}$ & $\begin{array}{l}\text { 2.Conceitos } \\
\text { internalizados pela } \\
\text { professora Laura }\end{array}$ & $\begin{array}{lr}3.0 \text { processo } & \text { de } \\
\text { interação } & \text { e/ou } \\
\text { mediação pedagógica }\end{array}$ & $\begin{array}{l}\text { 4.A participação e a } \\
\text { aprendizagem dos } \\
\text { alunos }\end{array}$ \\
\hline $\begin{array}{l}\text { - Início dos estudos do } S W \text { no } \\
\text { CAPI; } \\
\text { - Organização interna do } \\
\text { CAPI (horários, } \\
\text { atendimentos, aulas etc); } \\
\text {-Planejamento da professora. }\end{array}$ & $\begin{array}{l}-S W \quad \text { (conceito, } \\
\text { função social, } \\
\text { características, } \\
\text { parâmetros); } \\
\text {-Bilinguismo; } \\
\text {-Letramento. }\end{array}$ & $\begin{array}{l}\text {-Interação; } \\
\text { Intervenção/mediação. }\end{array}$ & $\begin{array}{l}\text {-Conceitos } \\
\text { internalizados; } \\
\text { - Percepção do } \\
\text { processo de } \\
\text { aprendizagem; } \\
\text { - A "responsividade } \\
\text { ativa". }\end{array}$ \\
\hline
\end{tabular}

Neste artigo, apresentamos os dados das categorias 01 e 02. Todo o processo de construção metodológica pode ser exemplificado conforme a figura a seguir:

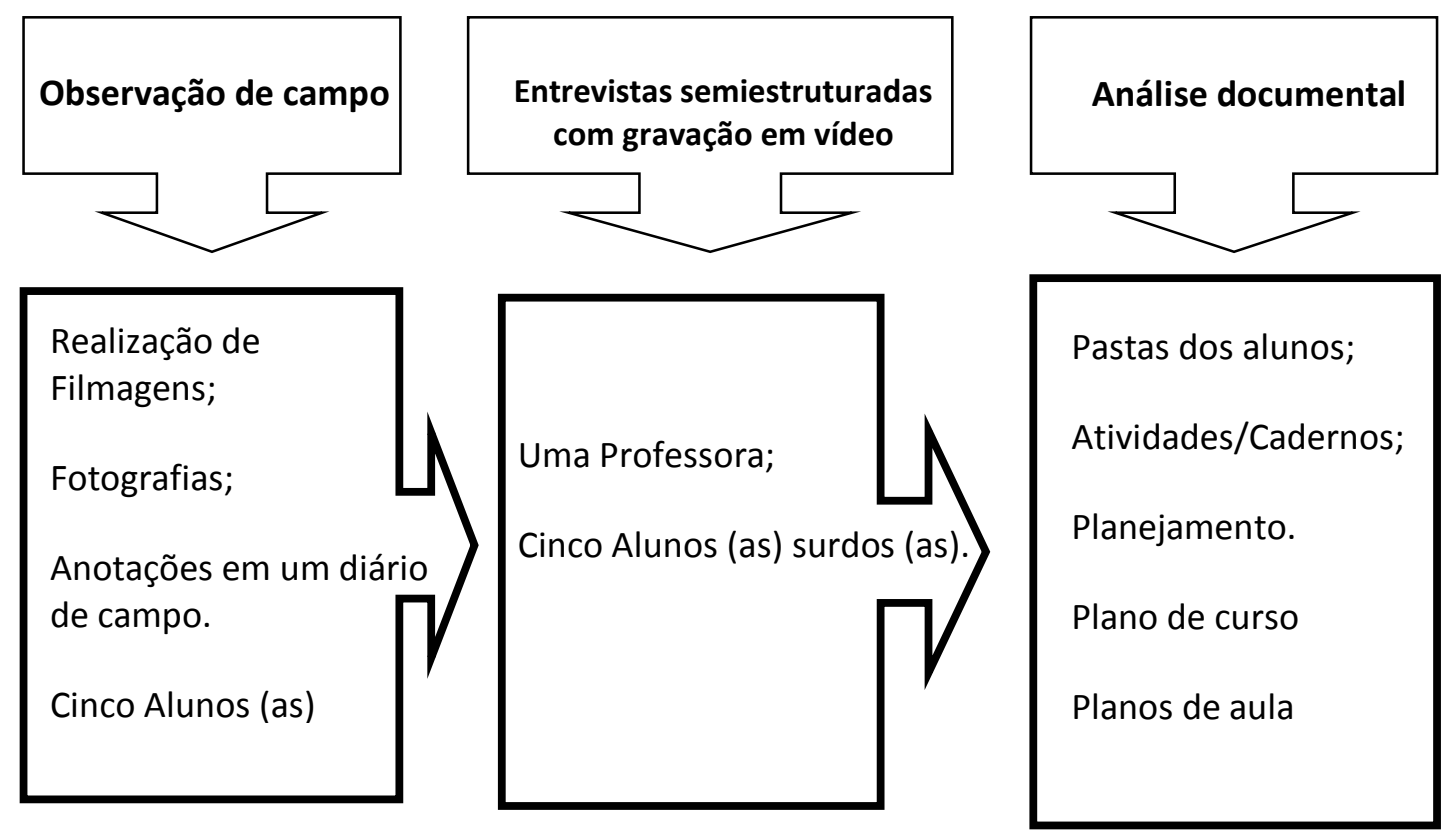

A pesquisa foi aprovada pelo Comitê de Ética em Pesquisa (CEP/UESB). 


\section{Resultados e discussão: Apresentando o CAPI}

Segundo Wanderley e Stumpf (2016, p. 147), "a escrita de sinais do SignWriting (SW) é um sistema alfabético de glifos que representa as línguas de sinais naturais, originado a partir de um sistema de notação de dança desenvolvido por Valerie Sutton”. Esse sistema foi criado em 1974, no Center for Sutton Moviment Writing, na Califórnia, USA, a partir de um sistema para notação de dança chamado DanceWriting criado em 1972, adaptando mais tarde para o sistema que ficou amplamente conhecido como SignWriting. E que há países que trabalham a $S W$ juntamente com o ensino da língua de sinais na educação de crianças surdas há muito tempo, partindo dos primeiros anos de escolarização.

A organização dos atendimentos no CAPI funciona diariamente nos turnos matutino e vespertino, com três atendimentos por turno, com sessenta (60) minutos de duração em cada atendimento. Os alunos são atendidos individualmente, em duplas ou trios, dependendo da especificidade e do tipo de atendimento oferecido em cada horário. Os professores buscam otimizar o tempo de atendimento proporcionando atividades direcionadas e previamente planejadas para cada aluno e/ou nível trabalhado.

Na área de surdez no CAPI os alunos são divididos por nível de proficiência em Libras, ou seja, cada aluno apresenta um nível diferente para cada atendimento: a) inicial; b) intermediário; e c) avançado. Basso; Strobel; Masutti (2009, p. 21) caracterizaram esses níveis da seguinte forma:

Nível básico - compreende o ensino voltado àqueles alunos surdos que têm pouco ou nenhum conhecimento de LIBRAS e da cultura surda. Neste nível enquadram-se tanto os alunos surdos da Educação Infantil (de o a 6 anos), quanto jovens e adolescentes surdos que iniciam tardiamente sua escolarização no Ensino Fundamental ou na Educação de Jovens e Adultos. Consideramos que os objetivos e os conteúdos para este nível são os mesmos para as diferentes faixas etárias, porém, as estratégias e recursos de ensino, bem como os critérios e formas de avaliação devem ser diferenciados.

Nível intermediário - compreende o ensino voltado aos alunos surdos que, independentemente de sua idade, têm contato com a comunidade surda, faz uso freqüente da língua de sinais e domina estruturas simples da língua. Neste nível enquadram-se os alunos surdos que tiveram contato com a LIBRAS desde pequenos, os adolescentes surdos que estudam em escolas de ouvintes, mas mantêm contato com surdos adultos com certa freqüência e os adultos surdos que freqüentam a Educação de Jovens e Adultos.

Nível avançado - compreende o ensino voltado àqueles alunos surdos que fazem uso mais elaborado da língua de sinais e que a compreendem como objeto de conhecimento e produto cultural. Neste nível enquadram-se os alunos surdos adultos que reconhecem a LIBRAS como a língua que expressa sua identidade cultural e que buscam um conhecimento mais aprofundado de LIBRAS, da história e da cultura surda.

No nível inicial o uso dos sinais pelos alunos se configura como dialeto na sociolinguística porque ainda não existe contato comunicativo em Libras na comunidade surda e não há conhecimento da cultura surda. A percepção visual desses alunos ainda é limitada. 
Com os atendimentos e o passar do tempo, eles vão adquirindo vocabulário, desenvolvendo a comunicação básica, buscando ampliar o léxico para melhorar o processo comunicativo. Ainda assim, eles não constroem grandes períodos, o nível linguístico revela construções sintáticas simples. O estudo da fonologia e morfologia se iniciam por meio do sistema $S W$.

No nível intermediário os sujeitos surdos participantes têm mais frequência e contato na sala de aula com surdos e professores, efetivando a interação no contexto de desenvolvimento de nível linguístico, assim é perceptível que esses alunos já fazem construções de frases e conseguem desenvolver pequenos diálogos em Libras. Esse desenvolvimento é resultado dos estudos e do contato com a língua de sinais.

No nível avançado os alunos buscam mais conhecimento para desenvolver a fluência na língua de sinais, mas é necessário continuamente buscar novas fontes de conhecimento, por exemplo a mídia, vendo sinais, aprendendo vocabulário e efetivando construções sintáticas mais complexas.

O CAPI proporciona para os alunos esse contato com a língua de sinais. São realizados 3 atendimentos de 60 minutos. Depois desse período, os alunos voltam para suas casas e comunidades, onde normalmente não tem contato com a língua de sinais. Esse fator é determinante para o desenvolvimento do léxico e da cognição desse aluno.

O aluno surdo participa de três atendimentos por dia: 1) Língua Portuguesa como segunda língua, 2) Libras e SignWriting e 3) Apoio Pedagógico. É importante ressaltar que o apoio pedagógico busca reforçar os conteúdos e atividades que foram passadas na escola regular e orientar os conhecimentos matemáticos.

\section{Organização pedagógica da escola e das atividades didáticas}

A professora Laura (nome fictício), é graduada em Letras e especialista em educação especial tornou-se profissional da educação de surdos há aproximadamente dez anos.

Nos diálogos iniciais em Libras percebemos que possui grande sensibilidade e envolvimento em relação à educação dos surdos. Embora tenhamos elaborado um roteiro de entrevista, não o seguiremos linearmente, pois durante a entrevista intercalamos novas perguntas. Assim, com intuito de entendermos o início dos estudos do $S W$ no CAPI, perguntamos sobre o sistema de educação para os surdos e a professora Laura nos respondeu:

P1: Eu comecei a trabalhar ensinando português para surdos, e eu percebi que os surdos têm muita dificuldade. Então eu tive uma ideia, de que os surdos precisavam ter um sistema que estivesse vinculado à língua de sinais. Então eu pesquisei e encontrei o SW, observei as combinações e por isso os surdos conseguem ler e escrever a própria da língua de sinais, porque o desenvolvimento cognitivo se torna fácil, o cérebro manda as orientações corretas em apenas uma língua. É emocionante porque em palavras, palavras, não havia combinação na língua. Mas a escrita da língua de sinais proporciona

ISSN 2526-2882

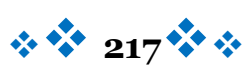


isso, ler e escrever na própria língua de comunicação, ajudando a organizar pensamento e as ideias.

Essa narrativa nos faz perceber que o fator preponderante para que os alunos tivessem contato com o $S W$ nessa unidade escolar foi justamente o interesse e a sensibilidade da professora. Ela pesquisou e estudou objetivando proporcionar melhores estratégias para que o ensino se tornasse mais efetivo.

Em seguida, Laura discute sobre a obrigatoriedade da aprendizagem da língua portuguesa para surdos. Ela enfatizou que:

P1: No Brasil as pessoas acreditam que os surdos precisam obrigatoriamente aprender português, mas essas pessoas não sabem que as línguas são diferentes. A gramática é totalmente diferente, por isso os surdos têm dificuldade para aprender português. Porém, se o surdo estuda a escrita própria de sua língua é diferente, porque ele pensa em língua de sinais e escreve em língua de sinais, tudo se combina, é muito melhor o desenvolvimento e o pensamento fica muito mais organizado. Depois o surdo pode mudar e fazer traduções para o português.

Em outra questão da entrevista, objetivando uma compreensão da forma como acontecia a rotina dos alunos surdos que estudavam no CAPI, perguntamos como era o atendimento e ela, pacientemente, explicou:

P1: Alfabetização bilíngue é diferente porque aqui no AEE tem três atendimentos diferentes, três salas diferentes, na primeira sala os alunos estudam Libras, alfabetização em Libras, escrita de sinais. Em outra sala eles estudam português, a alfabetização bilíngue permanece porque as aulas de português são trabalhadas em Libras. Na última sala eles têm atendimento de apoio pedagógico, onde eles estudam os conteúdos da escola inclusiva, usando também a Libras, então continua sendo bilíngue. Porque a L1 do surdo é a Libras, assim, ele precisa ter um momento exclusivo para estudar Libras, porque em casa ele não tem pessoas para ensinar, então ele precisa desse espaço próprio para desenvolver a prática da Libras e também da escrita da sua própria língua. Aqui no CAPI existe a ideia da proposta bilíngue, mas, os espaços são separados, entretanto, em todos os espaços a Libras é usada. Por isso é importante para a inclusão do surdo estar em um AEE responsável com a proposta bilíngue. Os surdos aprendem com mais facilidade quando usamos a Libras.

Em concordância com a explicação da professora Laura, contemplamos que a especificidade nos atendimentos é uma característica marcante nesta instituição. Além da sensibilidade desta professora, ainda percebemos a preocupação de cunho social em proporcionar aos alunos a vivência intensa em língua de sinais, visto que, em casa, com os familiares esse contato é restrito ou inexistente. A professora ainda enfatiza em suas falas a necessidade de sempre refletir sobre a prática pedagógica, a fim de aperfeiçoar o processo de ensino-aprendizagem. Pelo fato de se tratar de alunos surdos, trabalha-se com metodologias e 
prática direcionadas, ou seja, é importante avaliar as estratégias de ensino e a partir dos resultados dessa avaliação manter ou aperfeiçoar a prática refletindo assim sobre a interação entre aluno e professor no processo ensino e aprendizagem.

A professora Laura, no episódio 4, explica com clareza como acontecem os planejamentos e como se constroem as aulas, baseando-se nas estratégias da pedagogia visual, contemplando a percepção dos surdos:

P1: [...] No Capi eu uso a Pedagogia Visual, porque sabemos que o surdo precisa perceber as coisas visualmente. Todos os conceitos, as ideias, qualquer coisa, precisa ser percebido através do campo visual. Então todos os dias quando faço planejamentos, preciso lembrar que os surdos precisam ver os significados e explicações, a partir desta reflexão constante se constroem os planejamentos e a produção de material para as aulas.

A professora Laura fala sobre a necessidade de sempre refletir sobre a prática pedagógica, a fim de aperfeiçoar o processo de ensino-aprendizagem. Pelo fato de se tratar de alunos surdos, trabalha-se com metodologias e práticas direcionadas, ou seja, é importante avaliar as estratégias de ensino e a partir dos resultados dessa avaliação manter ou aperfeiçoar a prática. Permanecendo nessa linha metodológica, indagamos sobre quais as metodologias e estratégias são utilizadas para sistematização de aulas no processo de ensino e aprendizagem pelo sistema $S W$. A professora respondeu:

P1: [...] os alunos são atendidos nas aulas de escrita da língua de sinais/SW individualmente ou em duplas tendo apenas uma aula de 60 minutos por semana. Esse atendimento consiste em aulas expositivas/interativas baseadas na pedagogia visual, utilizando recursos concretos e/ou imagéticos.

Diante da colocação da professora Laura, é importante enfatizar a organização dos atendimentos, com no máximo dois alunos. Nessa configuração o professor consegue proporcionar uma aula direcionada, conseguindo também identificar com clareza as dificuldades de cada aluno.

Acerca do processo de aquisição da escrita através do sistema $S W$ como primeira língua para os surdos, perguntamos à professora Laura quais as vantagens e desvantagens. Ela esclareceu que: P1: [...] escrever a própria língua possibilita ao indivíduo surdo a organização do pensamento, criatividade e valorização da própria cultura e identidade promovendo o desenvolvimento da competência comunicativa.

Em linhas gerais, a professora aborda apenas as vantagens da aquisição da escrita através do sistema $S W$, e talvez esse seja o seu posicionamento diante da sua prática docente, visto que, em todos os momentos ela sempre se reportou à língua de sinais e sua escrita pelo sistema $S W$ com muito apreço e determinação. Entretanto a desvantagem real percebida é 
justamente a questão da aceitação dessa modalidade escrita para a língua de sinais, que ainda é pouco disseminada no Brasil. Todavia, o surdo estabelece uma relação de normalidade com a língua de sinais e sua modalidade escrita apenas completa essa relação, proporcionando um melhor desenvolvimento da competência comunicativa.

Questionamos a professora Laura a respeito dos registros (projetos, planejamento, fichas, tabelas, atividades, jogos, etc.) que ela dispõe para o ensino de $S W$ nessa escola. Ela explicou que:

P1: [...] no CAPI, temos a Proposta Curricular para o Ensino de Libras que engloba também o estudo da escrita da língua de sinais pelo sistema SignWriting. A partir dessa proposta, organizamos o Projeto de Atendimento Pedagógico e os planos de aula de acordo com o nível de proficiência do aluno (básico, intermediário e avançado), onde são registradas as estratégias de intervenção e atividades a serem realizadas.

A professora foi sucinta em sua resposta, especificando de onde parte a proposta para o ensino de $S W$ no CAPI. Entretanto podemos observar algumas fotografias do CAPI que configuram registros de materiais em $S W$ que contribuem para a aprendizagem dos alunos.

Figura 01 - Jogos e atividade em $S W$

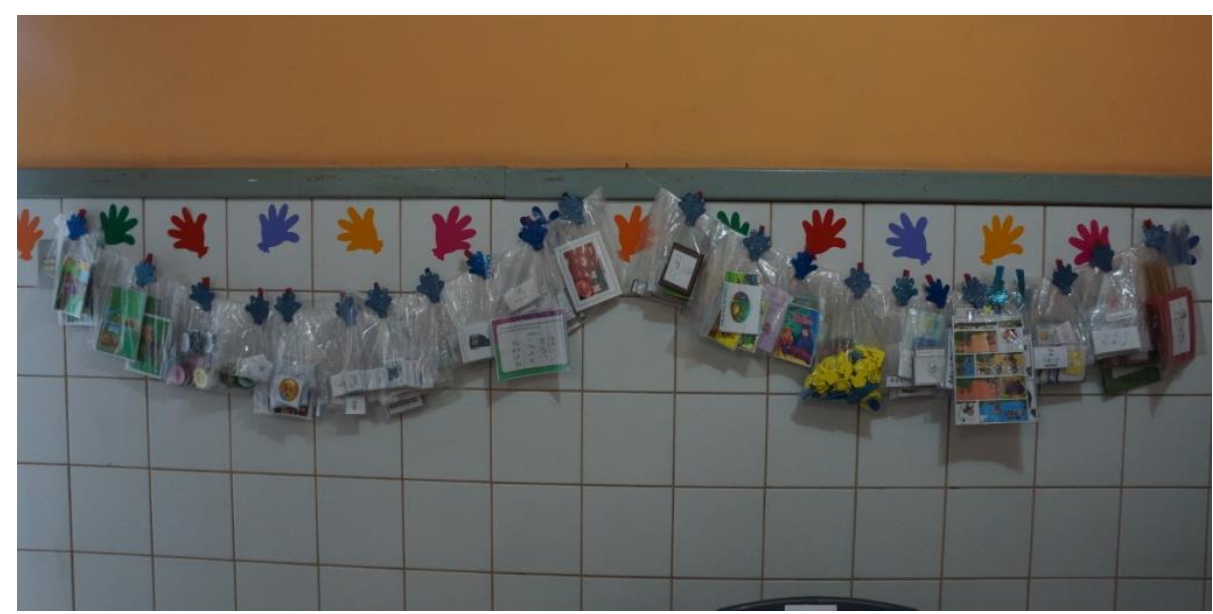

Fonte: Foto retirada pela pesquisadora

A figura 01 mostra vários jogos e materiais produzidos pelas professoras da área. Quando são planejados e construídos, a ideia é que eles possam ser utilizados em diversas atividades, assim esse varal é considerado como acervo de recursos e sempre que os professores propõem uma atividade eles recorrem ao varal para escolher um material adequado. 
Figura 02 - Ponto de vista do sinalizador (Movimento)

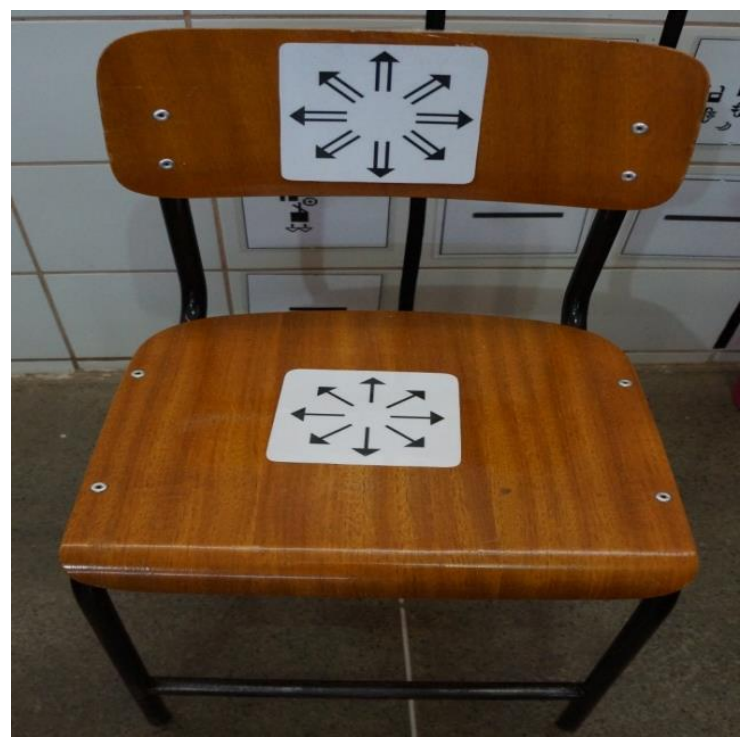

Fonte: Foto retirada pela pesquisadora

A figura 2 é uma cadeira com as imagens que representam o plano chão e o plano parede utilizado na escrita de sinais pelo sistema $S W$. Barreto e Barreto (2015) explicam essa característica acerca do movimento dos sinais.

Figura 03 - Atividade de leitura

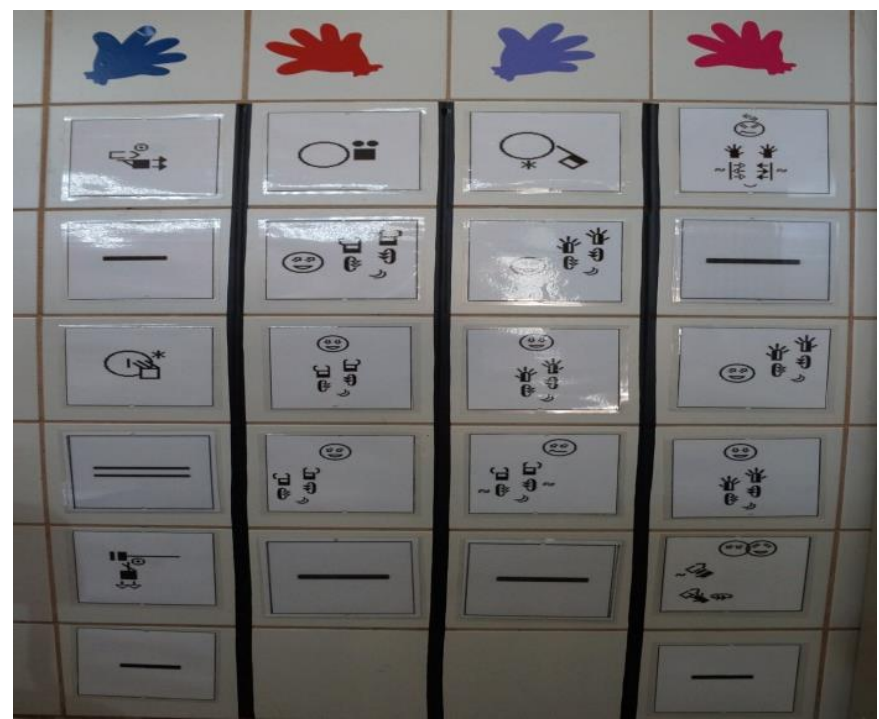

Fonte: Foto retirada pela pesquisadora

A figura 3 mostra um texto em $S W$ confeccionado em forma de mural na parede da sala. Fica acessível aos alunos para ler e observar os critérios para construção textual. O texto 
exposto foi retirado do livro de Barreto e Barreto (2015), visto que esse material é constantemente utilizado pelos professores do CAPI.

Figura 4 - EXPOCAPI

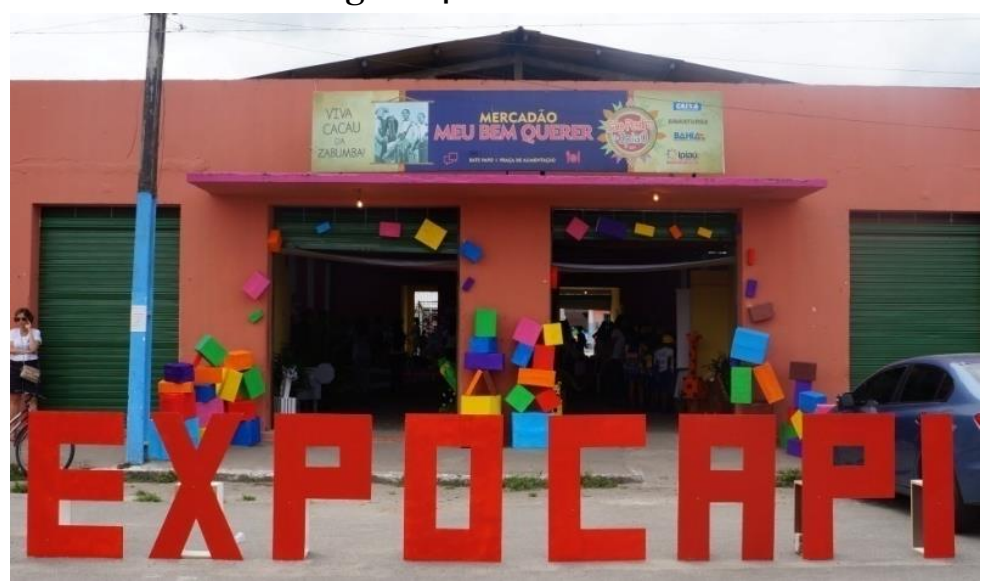

Fonte: Foto retirada pela pesquisadora

No período de observação no CAPI, estava acontecendo o evento EXPOCAPI (figura 4). Esta foi a terceira edição desta exposição, cujo objetivo era mostrar o trabalho desenvolvido durante o ano no CAPI. A EXPOCAPI fica aberta ao público da comunidade local. O CAPI escolhe um tema anual para direcionar os estudos e atendimentos e a EXPOCAPI mostra todas as atividades desenvolvidas durante o ano, as práticas pedagógicas e metodologias utilizadas. Em 2017, o tema foi Linguagem e Representação Matemática no Processo de Inclusão. Foram divulgadas diversas atividades nesse contexto. Fotografamos todo o evento, atividades e materiais expostos. Importante lembrar que também tinham algumas atividades interessantes em $S W$ com o tema Matemática.

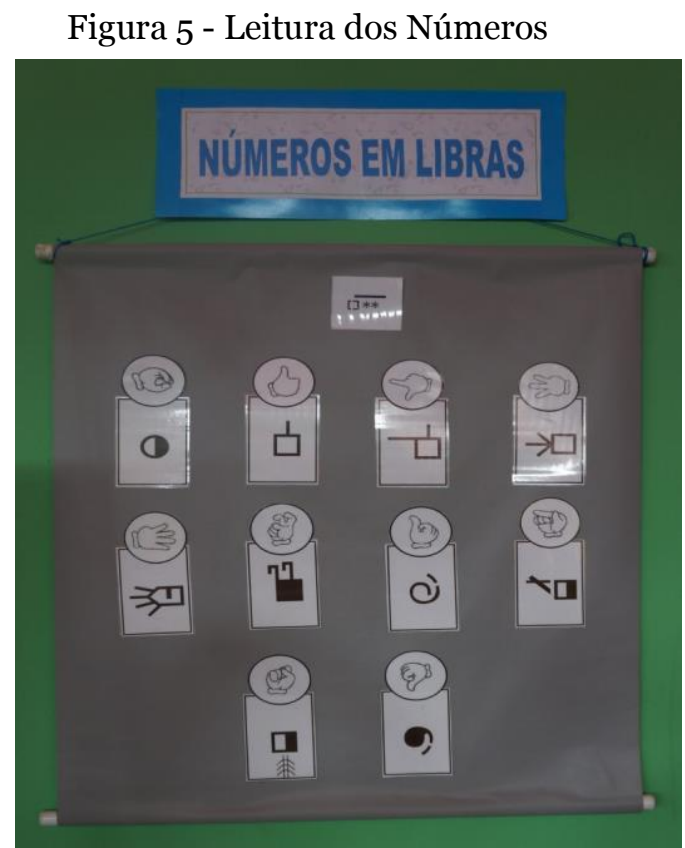

Fonte: Fotos retirada pela pesquisadora

ISSN 2526-2882

* $222 *$ 
A figura 5 mostra um painel com os números em Libras e em $S W$. Como o evento foi aberto à comunidade esse tipo de representação é interessante para que as pessoas compreendam como acontece a escrita de sinais dos numerais.

Figura 6- Jogo das Almofadas

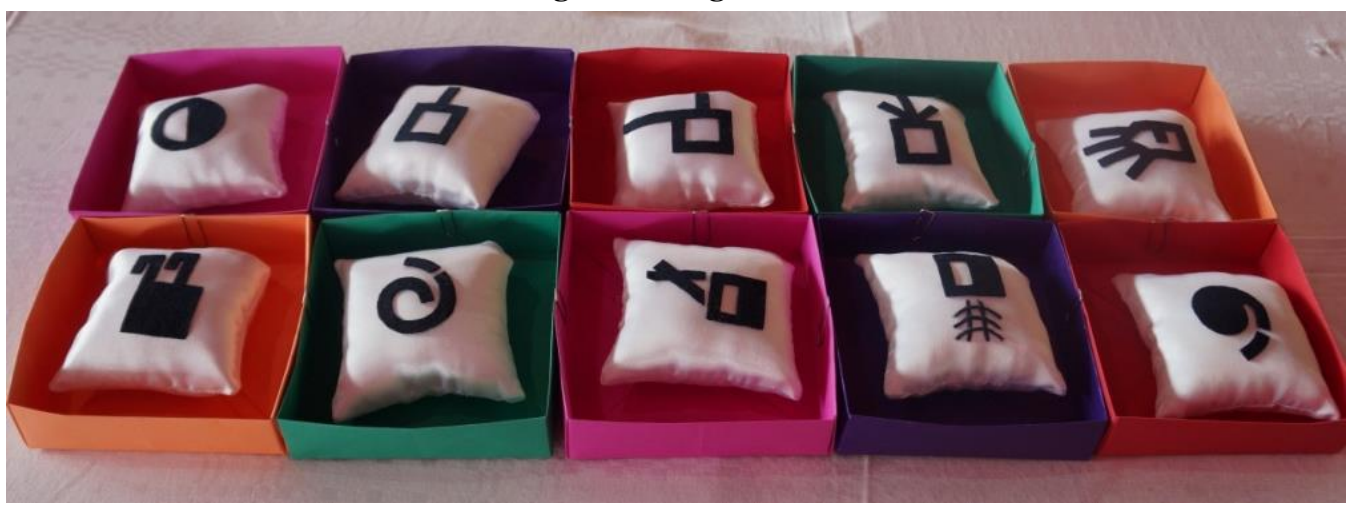

Fonte: Fotos retirada pela pesquisadora

A imagem acima mostra pequenas almofadas com os números escritos através do sistema $S W$. Essa é uma estratégia interessante porque os surdos observam o sinal e fazem correspondências. A professora usa esse material para fazer jogos de perguntas envolvendo números e a partir das respostas os alunos escolhem as almofadas correspondentes. Pelo fato de ser produzido em alto relevo, esse material fica exposto e pode ser manuseado por qualquer pessoa, inclusive pelos cegos. É importante frisar que ao utilizar esse material, a professora explica qual tipo de brincadeira que será feita e quais as regras, a partir dessas explanações os alunos surdos desenvolvem a atividade.

Figura 7 - Atividade jogo do calendário em $S W$

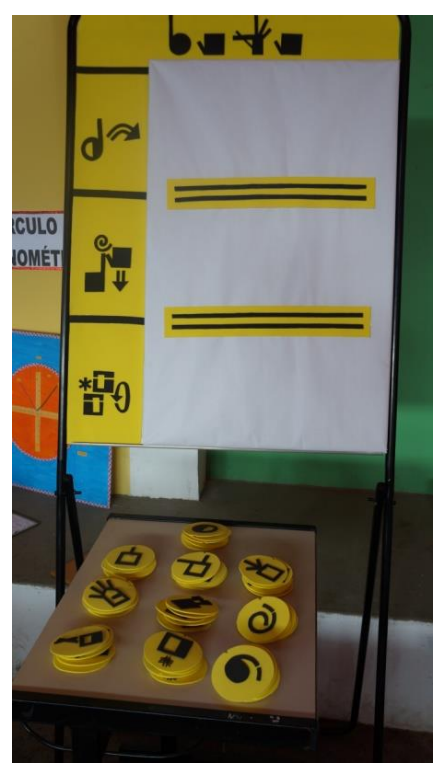

Fonte: Foto retirada pela pesquisadora

ISSN 2526-2882

$$
\text { * } 223 *
$$


O jogo do calendário é usado para que os alunos possam aprender a relacionar a data, separando os dados do dia, do mês e do ano. Então quando a proposta da aula contempla a utilização deste material, a professora Laura propõe uma atividade e o aluno deve pegar os sinais com os números e montar o calendário. Em alguns momentos eles colocarão apenas a data daquela aula, em outros, trabalharão datas de aniversário ou outras datas comemorativas.

Figura 8 - Jogo de números e sinais

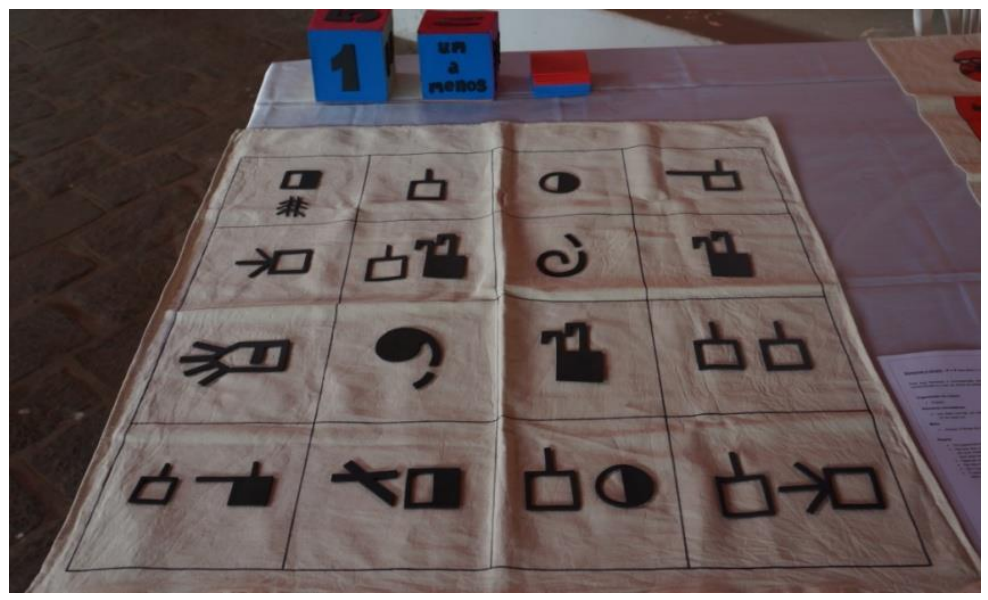

Fonte: Foto retirada pela pesquisadora usando câmera digital

O quadro a seguir mostra as regras do jogo de números e sinais (Figura 8)

Número e sinais $-4^{o}$ e $5^{\circ}$ ano (livro, 1, pág. 121)

Este jogo favorece a compreensão das escritas matemáticas, permite desenvolver a compreensão e o uso de sinais de desigualdade ( $>$ ou $<$ ).

Organização da classe:

- Duplas

Recursos necessários:

- Um dado normal, um dado de sinais, um tabuleiro, 20 fichas de duas cores, sendo 10 de cada cor.

\section{Meta:}

- Alinhar 3 fichas da mesma cor na horizontal, vertical ou diagonal.

Regras:

- Os jogadores decidem quem começa o jogo.

-Na sua vez, o jogador rolar os dois e cobre no tabuleiro um número que corresponde ao que mostra os dados. Por exemplo, se ele tirou (< e 3) ele cobre um número que seja menor que 3, com uma fica de sua cor.

- Apenas um número pode ser coberto a cada vez.

- Se não houver casa para colocar a ficha o jogador terá mais uma chance.

- Se o jogador cobrir o número errado, ele perde a vez.

- O primeiro jogador que alinhar três de suas fichas na horizontal, vertical ou diagonal será o vencedor.

Fonte: Dados de pesquisa - explicação da operacionalização do jogo de números e sinais. 
A explanação acima descreve como deve acontecer o jogo, então, antes de iniciar a partida, a professora orienta os alunos e explica as regras para que a atividade possa funcionar conforme o esperado.

Retomando o foco sobre leitura e escrita, perguntamos a professora Laura quais são as atividades feitas com os alunos surdos. Ela explicou que: P1: Trabalhamos com leitura, exploração da leitura e retextualização de livros que fazem parte da literatura surda, contendo a tradução de seus textos em SW [...]. Em relação às atividades de leitura a professora utilizou alguns materiais da literatura surda, conforme imagem a seguir:

Figura 9 - Literatura Surda

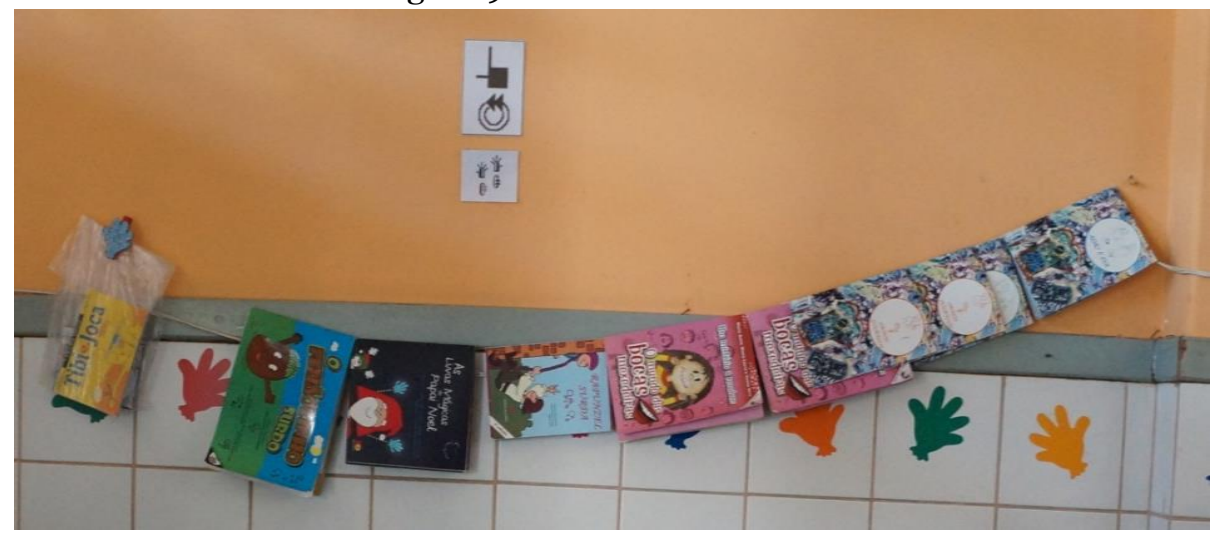

Fonte: Foto retirada pela pesquisadora usando câmera digital

Na sala de aula é possível observar alguns materiais expostos de literatura surda em $S W$. Os professores podem utilizar como material para as aulas e também estão à disposição dos alunos para ler e treinar sinais escritos. Assim, é muito importante reforçar a necessidade da prática da leitura por qualquer aluno, surdo ou ouvinte. Como é sabido que a Língua Portuguesa é a segunda língua para o surdo é necessário que este tenha um meio de leitura relacionado com sua língua. E essa identificação dos alunos surdos com a escrita de sinais por meio do sistema $S W$ é percebida desde o primeiro momento. Na imagem seguinte podemos observar a execução de uma atividade em $S W$ por uma aluna com a mediação da professora.

Figura 10 - Aluna surda A4 (Nível Avançado) fazendo atividade em $S W$

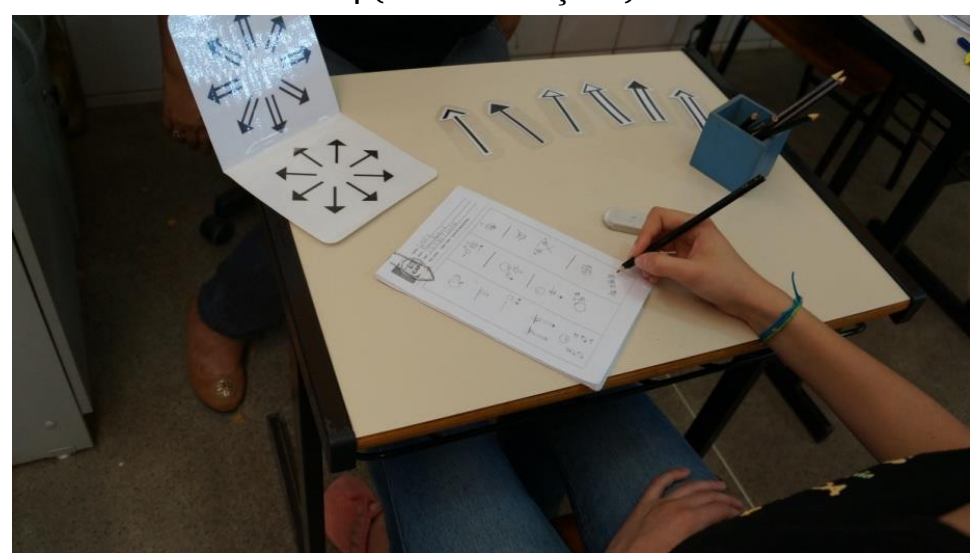

Fonte: Foto retirada pela pesquisadora usando câmera digital ISSN 2526-2882 
As atividades são desenvolvidas com mediação da professora em conformidade com as nossas constatações teóricas a respeito da interação e mediação. Sempre que necessário são usados materiais que tenham relação com os conteúdos trabalhados a fim de esclarecer regras no processo de escrita dos sinais.

Figura 11 - Atividade Carta para Camila (nome fictício) em $S W$

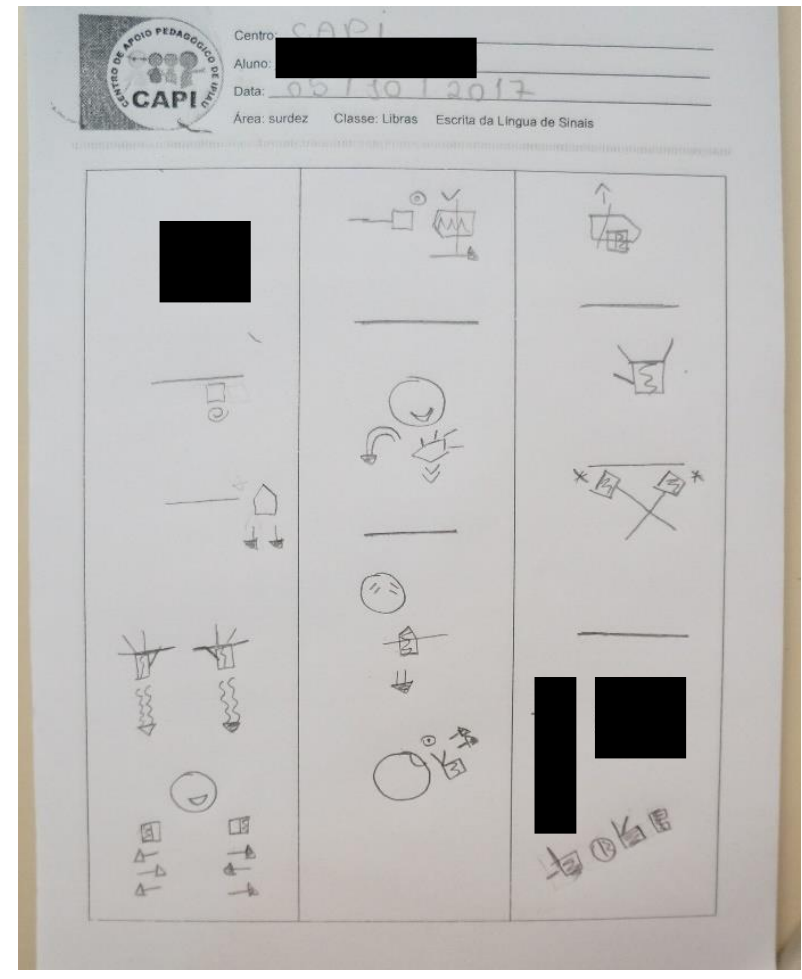

Fonte: Foto retirada pela pesquisadora usando câmera digital

\section{TRANSCRIÇÃO:}

SINAL (CAMILA); SAUDADE; PASSADO; FELIZ; ADORAR; CARINHOSA; BONITA; CRIANÇA; LEMBRAR; AJUDAR/APOIO; I LOVE YOU (empréstimo de ASL significa "eu amo você") ABRACAR; LOVE; SINAL ALUNA A4.

\section{TRADUÇÃO:}

Camila, eu vou sentir saudades, eu era feliz e adorava você. Você é carinhosa e bonita. Lembro quando eu era criança você me ajudava. Eu amo você, abraço! Com amor! A4

$$
\text { Fonte: Transcrição e tradução feita a partir da figura } 30 .
$$

É interessante perceber que diferente do português, a escrita em $S W$ obedece às regras gramaticais da Libras, ou seja, o aluno não precisa pensar em uma estrutura e organizar sua escrita em outra. Essa constatação é reforçada a partir dos estudos de Barreto e Barreto (2015) e Stumpf (2004 e 2005).

Entretanto, para a construção das atividades em $S W$ é necessário um software específico, nesse sentido, perguntamos à professora qual o programa que ela usa na confecção ISSN 2526-2882 
das atividades do CAPI. Ela respondeu: P1: [...] utilizo SignPuddle, gosto deste programa porque ele tem ferramentas que facilitam a tradução.

Falar sobre editores de texto para o sistema $S W$ ainda é complexo, pelo fato de ser algo novo, existem poucos recursos nessa área, entretanto, conhecemos dois editores de texto, o SignPuddle e o $S W$-Edit. O primeiro é usado com frequência nos sistemas tecnológicos e fica disponível online nas pesquisas sobre $S W$. Em contrapartida, o segundo não foi atualizado, por esse motivo não é muito utilizado, porque não consegue acompanhar a evolução e dinamicidade da língua. Vejamos os ambientes virtuais de cada um desses editores:

Figura 11- SignPuddle Online

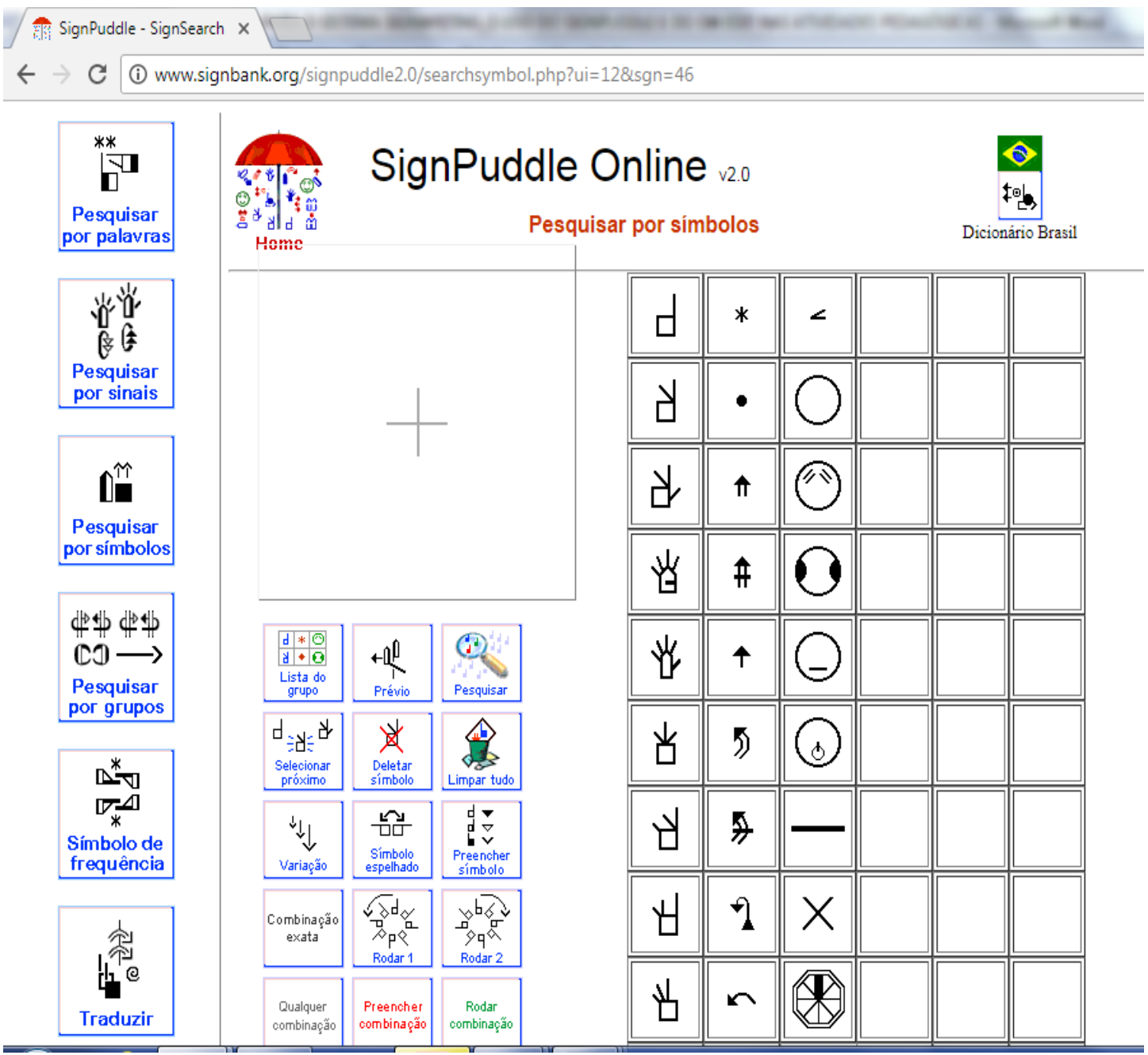

Fonte: http://www.signbank.org/signpuddle2.o/searchsymbol.php?ui=12\&sgn=46 
Figura 12 - O Software $S W$-Edit

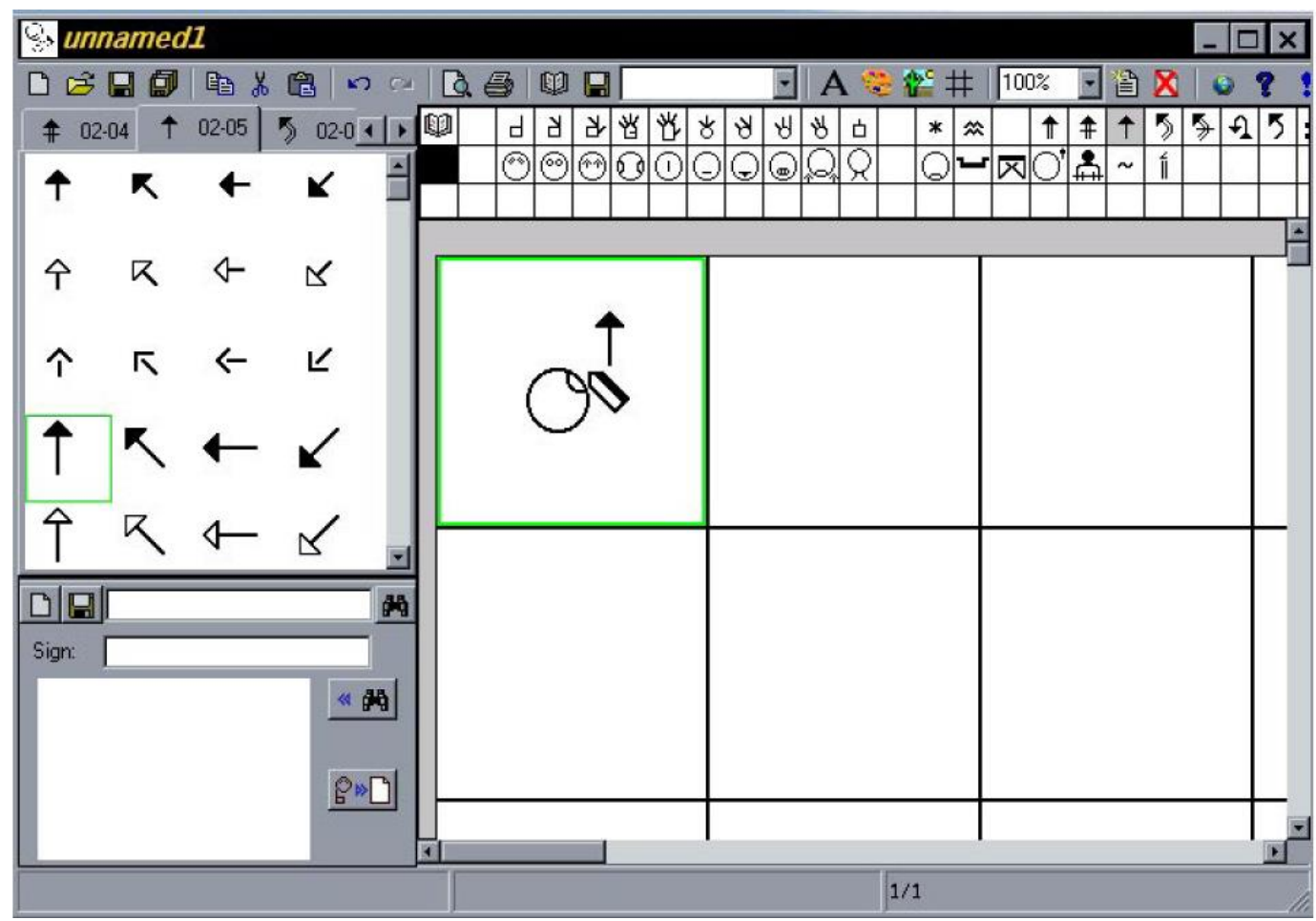

Fonte:http://www.signwriting.org/forums/software/archive/softarc11.html

A professora organiza os planejamentos com antecedência de acordo com o conteúdo e a escolha do tema. O uso do SignPuddle online na internet, organiza visualmente a edição de texto para criar atividade de Escrita de Sinais, contendo questões e respostas sobre Literatura Surda. A figura 13 evidencia o uso desse sistema no processo ensino/aprendizagem de alunos surdos.

Figura 13 - Atividade de $S W$

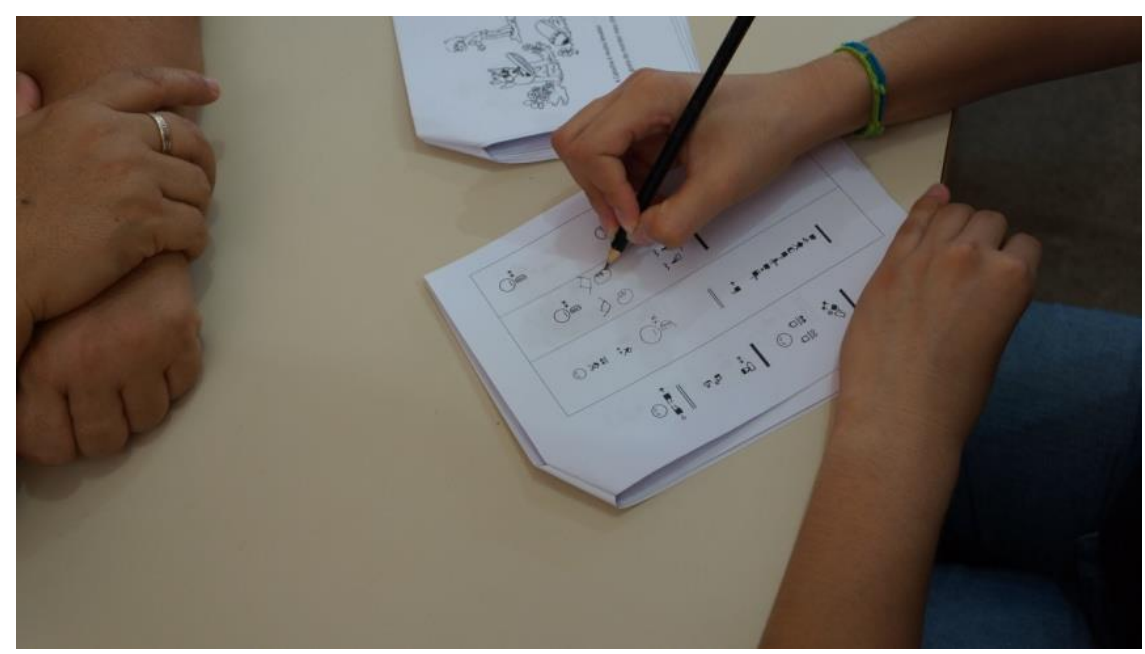

Fonte: Fotos do acervo da pesquisadora

ISSN 2526-2882

$* 228 *$ 
Essa figura mostra a atividade com uma aluna no CAPI. A professora explica o significado das questões e solicita as respostas. A atividade é uma forma de treinar a escrita em $S W$. É importante ressaltar que a relação de interação entre professor e aluno é muito importante nesse processo de aquisição e construção de conhecimento. Os registros dos estudos de Bakhtin (2012) não deixam dúvidas de que a interação é algo vital para o ser humano e no contexto escolar esse contato é ainda mais produtivo, incentivando a construção de conhecimento.

Diante das questões já exploradas podemos perceber que no âmbito pedagógico há uma organização e um direcionamento característico que acompanha o projeto curricular da instituição e também as aulas de escrita de sinais.

Perguntamos à professora qual a avaliação que ela faz do ensino realizado com os alunos. Expressando satisfação, ela respondeu:

P1: Percebo claramente que os alunos se identificam com a escrita da Libra pelo sistema SW pois demonstram alegria ao ler cada sinal ou texto e entendem o que está escrito sem grandes dificuldades. Mesmo os alunos que apresentam-se no nível básico de proficiência da Libras fazem associação fonema/grafema e ao se depararem com a escrita fazem tentativas de leitura.

É fato que os alunos surdos se sentem realizados ao conhecer a escrita de sinais pelo sistema $S W$, porque existe uma identidade que permeia todo esse processo linguístico. Assim, estudiosos afirmam que mesmo iniciantes em $S W$, conseguem associar sinais à sua escrita e estabelecer a relação fonema/grafema. A resposta da professora Laura reforça as afirmações de Stumpf (2005) de que a escrita utilizando o sistema $S W$ acontece de forma natural para o surdo.

\section{Considerações finais}

Neste artigo apresentamos os resultados de uma pesquisa que analisou a prática pedagógica com o sistema de leitura e escrita desenvolvida por uma professora com estudantes surdos, em uma escola pública de Ipiaú-Bahia.

Os dados evidenciam que a prática desenvolvida pela professora propicia o processo de ensino-aprendizagem pelos estudantes. Percebemos que no CAPI há uma nova perspectiva e novas estratégias de ensino entre as áreas de atendimento para os surdos, relacionando-se e proporcionando melhor desenvolvimento. Observamos também a afinidade dos alunos surdos com o SW desde que tiveram o primeiro contato.

Sobre a postura da professora e a relação estabelecida com os alunos ela demonstrou em todo o tempo muito esforço na proposta de ensinar os surdos através do sistema SW. Foi possível contemplar que existe uma profunda observação por parte da professora a respeito 
dos alunos, ela consegue compreender suas dificuldades e alcança êxito nas propostas por conta da sua dedicação profissional.

\section{Referências}

BAKHTIN, Mikhail (Volochinov). Marxismo e Filosofia da Linguagem. 12. ed. São Paulo: Hucitec, 2012.

BARRETO, M. BARRETO, R. Escrita de sinais sem mistérios. Vol. I. 2. ed. red. atual. e ampl. - Salvador, v1: Libras Escrita, 2015.

BASSO, I. M. de S; STROBEL, K. L.; MASUTTI, M. Metodologia do Ensino de Libras L1. Florianópolis: UFSC, 2009.

LOIZOS, P. Vídeo, filme e fotografias como documentos de pesquisa. In: BAUER, M. W.; GASKELL, G. (Orgs.). Pesquisa qualitativa com texto, imagem e som. 2. ed. Petrópolis: Vozes, 2008. p. 137-155.

MINAYO, Maria. C. de Souza. O desafio do conhecimento: pesquisa qualitativa em saúde. 6. ed. São Paulo: Hucitec; Rio de Janeiro: Abrasco, 2002.

SILVA, Fábio I. da. Analisando o processo de leitura da uma possível escrita da língua brasileira de sinais: SIGNWRITING. Dissertação de mestrado em Educação. Florianópolis: UFSC, 2009.

STUMPF, Marianne. Aprendizagem de escrita de língua de sinais pelo sistema signwriting: Línguas De Sinais No Papel e no Computador. Porto Alegre: UFRGS, 2005. Tese (Doutorado Em Informática Na Educação), Pós-Graduação Em Informática Na Educação, Universidade Federal Do Rio Grande Do Sul, 2005.

STUMPF, Marianne R. Sistema SignWriting: por uma escrita funcional para o surdo. In: THOMA, Adriana da Silva; LOPES, Maura Corcini (Org.). A invenção da surdez: cultura, alteridade, identidade e diferença no campo da educação. Santa Cruz do Sul: EDUNISC, 2004.

STUMPF, Marianne. R. Letramento na língua de sinais Escrita para Surdos. In: MOURA, M. C. de; CAMPOS, S. R. L. de; VERGAMINI, S. A. A (org.). Educação para Surdos: Prática e Perspectivas II. São Paulo: Santos, 2011.

WANDERLEY, Débora C; STUMPF, Marianne R. A marcação do plural no sistema SignWriting. Línguas de Sinais: abordagens teóricas e aplicadas. Revista Leitura, vol.1, nº 57, p. 147-171, jan/jun 2016.

WANDERLY, Débora C. A leitura de escrita de sinais de forma processual e lúdica. 1 ed. Curitiba: Editora Prismas, 2015. 


\section{Biografia Resumida}

Fabíola Morais Barbosa: Licenciatura em Letras com habilitação em Língua Brasileira de Sinais, pela Universidade Federal de Santa Catarina. Mestre em Ensino (UESB). Professora de Libras da Universidade Federal do Recôncavo da Bahia (UFRB).

Link do Lattes: http://lattes.cnpq.br/3381997630021198 e-mail: bibidabahia@gmail.com

Maria Aparecida Pacheco Gusmão: Licenciada em Letras (UESB). Doutora em Educação (UFRN). Professora da Universidade Estadual do Sudoeste da Bahia e do Programa de Pós-graduação em Ensino (PPGEn/UESB).

Link do Lattes: http://lattes.cnpq.br/o811302121043675 e-mail:prof.cida2011@gmail.com 